\title{
Comparative of Study the Design Spectra Defined by Various Seismic Codes
}

\author{
K Hadar Elmi ${ }^{1}$, Erdal Coskun ${ }^{2}$ \\ 1- Institute of Graduate, Structural Engineering Program Istanbul Kultur Universitesi \\ 2- Department of Civil Engineering İstanbul Kultur Universitesi.
}

\begin{abstract}
Seismic codes provide to achieve desired performance that structure withstands the earthquake loads with minimum requirements. Many standard building codes developed and imposed to minimize damage and to ensure life safety and economic loss. In seismic regions, seismic design is very conscious. However, the lack of seismic design codes, engineers depends on the internation al guidelines. Therefore it is imperative to compare the international design codes once the building codes developed. To mitigate the hazard of earthquakes is the primary purpose used for seismic codes. The main objective of this study is to compare the vario us seismic codes defined by design spectra, and some fundamental points are defined generally included the elastic design spectra, seismic hazard specification. In this study, a particular site has chosen to achieve the comparison codes. The result obtaine d by the design codes compared and highlighted by the similarity and difference among them, such as base shear, interstory drift, and displacement. The dynamic linear analysis used to implement the design to achieve the objectives. The analysis is performed in SAP 2000. V20.
\end{abstract}

Keywords: Comparative Seismic Codes, Elastic Design Spectra, Soil Classification, Seismic Hazard Specification and Base Shear

\section{INTRODUCTION}

Turkey is considered the most active seismic regions in the world, surrounded by different plates. In the past two decades, two strong earthquakes happened in Turkey (Kocaeli and Düzce), remarkably over 51,000 buildings were damaged or collapsed, and more than 18,000 have died [1] [2]. However, after that strong earthquake are revised the code and produced another seismic code which more confidential the previous building code. The material used for the design structures were poor and also not probably designed for structures as well as the magnitude of the earthquake is the major problems that cause this heavily casualties both for structures and human. In Van earthquake (2011), more than 604 lost their lives, and 1301 people got injured [3].

The past studied for the earthquake recognized that lateral loads are essential than the designing structures for a gravity load only. The standard seismic codes used for a force-based design for elastic analysis, while a designed an earthquake resistance design, however, the structure experienced more displacement during the strong earthquakes and expected to behave for nonlinear and energy dissipating is essential to account for that the displacement-based design developed later. The main seismic codes established to reduce the catastrophic of earthquakes and to preserve structures can resist the earthquake loads. In the prediction of future earthquakes, it is imperative to define the seismic loads to recognize that structures withstand the earthquake loads.

For a short period, earthquake induces forces that are significant structure able to withstand without damage or collapse. Structures should be able to resist the small magnitude with minor damage to reduce maintenance costs. Building codes provide to achieve desired performance that structure resists the earthquake loads with the least requirements. Many standard building codes developed and imposed to minimize damage and to ensure life safety and economic loss. In seismic regions, seismic design is very conscious. However, the lack of seismic design codes, engineers depends on the international guidelines. Therefore it is imperative to compare the international design codes once the building codes developed [4].

To evaluate the similarity and dissimilarity among seismic codes, many researchers have compared several seismic codes Tariq Nahass (2017) compared Saudi building code and UBC 1997 code to assess the resemblances and differences between these codes and methods of analysis done by modal response spectra and equivalent lateral force methods [5]. The response spectrum originated by Boit and advanced by Housner, and the theory of response spectrum earthquake engineers uses to estimate the peak response of a single degree of freedom system [6] [7] [8].

\section{SEISMIC HAZARD SPECIFICATION}

The hazard is defined in terms of a single parameter, and Eurocode uses reference peak ground acceleration on type A ground $a \mathrm{gR}$. The country's national Annex found this parameter and derived for seismic zonation. The National Authorities chosen by reference peak ground acceleration for each seismic code corresponds to the reference return period. Eurocode recommended the return period for non-collapse performance level 475 year corresponding to 10\% probability of exceedance in 50 [9]. United States Geological Survey (USGS) prepared by seismic maps are used to construct design spectra corresponding to the maximum considered earthquake (MCER) and earthquake design base. The probabilistic MCER earthquake proposed has a 
probability of exceedance of $2 \%$ in 50 years ( 2475 reoccurrence period) and the earthquake design base represented by $10 \%$ years in 50 years for return period 457 years. The new Turkish seismic code defined four different ground motion levels, DD-1: $2 \%$ probability of exceeding in 50 years, and recurrence is 2475 , DD-2: $10 \%$, probability of exceeding in 50 years, and recurrence is 475, DD-3: $50 \%$ probability of exceeding in 50 years, and recurrence is 72 and finally DD-4: $50 \%$ probability of exceeding in 50 years, and recurrence is 43 [10].

\section{SOIL CLASSIFICATION}

The response of structures, local soil conditions becomes a vital role. After conducting a research study for earthquakes, Loma Prieta 1989, Northridge 1994, and Kobe 1995 and other earthquakes, seismic building codes recognized the importance of local site conditions. The rock and soil at a site have particular features that can ominously amplify the incoming earthquake motions traveling from the earthquake source [11]. The structures with a similar construction type, it was detected that structures with deep soils are more damaged than the structures with founded by on rock. Building codes define different categories into account the site effects. The most useful parameter for site classification is Vs.30 and describes the average shear wave velocity of the upper $30 \mathrm{~m}$ of the soil profile. According to the EC8 code, VS.30 parameter uses to classify the soil along with NSTP and plasticity index PI and undrained shear strength CU. Eurocode expresses five ground types (A to E) along with two soil factors [12]. Turkish code considers similar to the Eurocode and uses Vs.30 to classify the soil classes [13]. The new Turkish code defines a five soil classes varying A to E. The American code ASCE7-16 considers both undrained shear strength and Vs.30 to classify the soil classes. The soil classes ASCE7-16 varying A to E. Table 1 shows the soil classes according to these seismic codes.

Table 1 Soil Classification

\begin{tabular}{|c|c|c|c|}
\hline Soil Classification & \multicolumn{3}{|c|}{ Seismic Code Design } \\
\hline & EC8 & ASCE7-16 & TSC-2018 \\
\hline A & $\begin{array}{l}\text { Rock or other rock- } \\
\text { Vs }>800 \mathrm{~m} / \mathrm{s}\end{array}$ & Hard Rock Vs > 1524 m/s & Rugged, hard rocks Vs > $1500 \mathrm{~m} / \mathrm{s}$ \\
\hline B & $\begin{array}{l}\text { dense sand, gravel, } 360 \mathrm{~m} / \mathrm{s}<\mathrm{Vs}< \\
800 \mathrm{~m} / \mathrm{s}\end{array}$ & Rock $762 \mathrm{M} / \mathrm{S}<\mathrm{Vs}>1524 \mathrm{~m} / \mathrm{s}$ & $\begin{array}{l}\text { Slightly weathered, medium solid rocks } 760 \mathrm{~m} / \mathrm{s}< \\
\text { Vs }>1500\end{array}$ \\
\hline $\mathrm{C}$ & $\begin{array}{l}\text { Deep deposits of dense or medium } \\
\text { dense sand, gravel or stiff clay } \\
180 \mathrm{~m} / \mathrm{s}<\mathrm{Vs}<360 \mathrm{~m} / \mathrm{s}\end{array}$ & Very Dense Soil 366 m/s < Vs $>762 \mathrm{~m} / \mathrm{s}$ & $\begin{array}{l}\text { Very tight layers of sand, gravel, and hard clay, or } \\
\text { weathered, cracked weak rocks } 360 \mathrm{~m} / \mathrm{s}< \\
\text { Vs.> } 760 \mathrm{~m} / \mathrm{s}\end{array}$ \\
\hline D & $\begin{array}{l}\text { Deposits of loose-to-medium } \\
\text { cohesionless soil Vs. }<180 \mathrm{~m} /\end{array}$ & Stiff Soil $183 \mathrm{~m} / \mathrm{s}<\mathrm{Vs}>366 \mathrm{~m} / \mathrm{s}$ & $\begin{array}{l}\text { Medium tight - layers of tight sand, gravel or very } \\
\text { solid clay } 180 \mathrm{~m} / \mathrm{s}<\mathrm{Vs} \\
>360 \mathrm{~m} / \mathrm{s}\end{array}$ \\
\hline E & $\begin{array}{l}\text { A surface of alluvium layer with a } \\
\text { water table } \\
\text { a layer of Type C or D on Rock }\end{array}$ & Soft Soil Vs > $366 \mathrm{~m} / \mathrm{s}$ & Loose sand, gravel, or soft Vs. $<180 \mathrm{~m} / \mathrm{s}$ \\
\hline $\mathrm{S} 1$ & $\begin{array}{l}\text { A layer of at least } 10 \mathrm{~m} \text { thick, } \\
\text { soft clays/silt }\end{array}$ & \begin{tabular}{l|l} 
F & requiring site-specific \\
research and evaluation
\end{tabular} & $\begin{array}{l}\text { Floors requiring site-specific research } \\
\text { and evaluation }\end{array}$ \\
\hline
\end{tabular}

\section{ELASTIC DESIGN SPECTRA}

The response spectrum is a widely accepted method for earthquake resistance design, and most seismic codes use. Earthquakes induce ground trembling that commonly epitomized by the form either acceleration or displacement response spectra. Magnitude, soil conditions, duration, and epicentral distance are earthquake parameters and influenced by the form and the amplitude of response spectra [14]. The elastic shape defined by Eurocode provides expressions in both vertical and horizontal components of seismic actions. The control points TB, TC, and TD and of the soil factor defined by the elastic spectrum shape depends on the ground type. The soil factors defined in Eurocode depends on the damping factor and ground type. The design spectrum derived from the elastic response spectrum based on no collapse adopting by modification factor q, which Eurocode called by behavior factor. The map prepared by USGS to estimate the seismic hazard covered the whole United States. Probabilistic and deterministic hazard spectra both considered. Once the seismic map provides the spectra values SS and S1 for short and long periods respectively, this information will use to determine the response spectrum curve, and soil amplification factors ( $\mathrm{Fa}$ and $\mathrm{Fv}$ ) used to modify the response spectrum curve. The design spectrum SMS and SM1 represented by short and long periods and are computed by $2 / 3 * \mathrm{MCER}$. The points TO and TS define the acceleration control region, and the points TS and

$1.0 \mathrm{sec}$ describe the velocity control region, and the corner TL defines where the displacement control region

started, however, Figure 1 describes the elastic design spectrum according to the ASCE7-16. The new Turkish seismic codes define spectral ordinates, and the seismic hazard map provides the spectral acceleration for short and long period SS and S1 for $\mathrm{T}=0.2 \mathrm{~s}$ and $\mathrm{T}=1 \mathrm{~s}$ respectively, to construct the elastic design spectra. The local soil coefficient used to modify the response spectrum to get spectral design acceleration SDS and SD1. The corner periods TA and TB found from the related ratios of SDS and SD1 


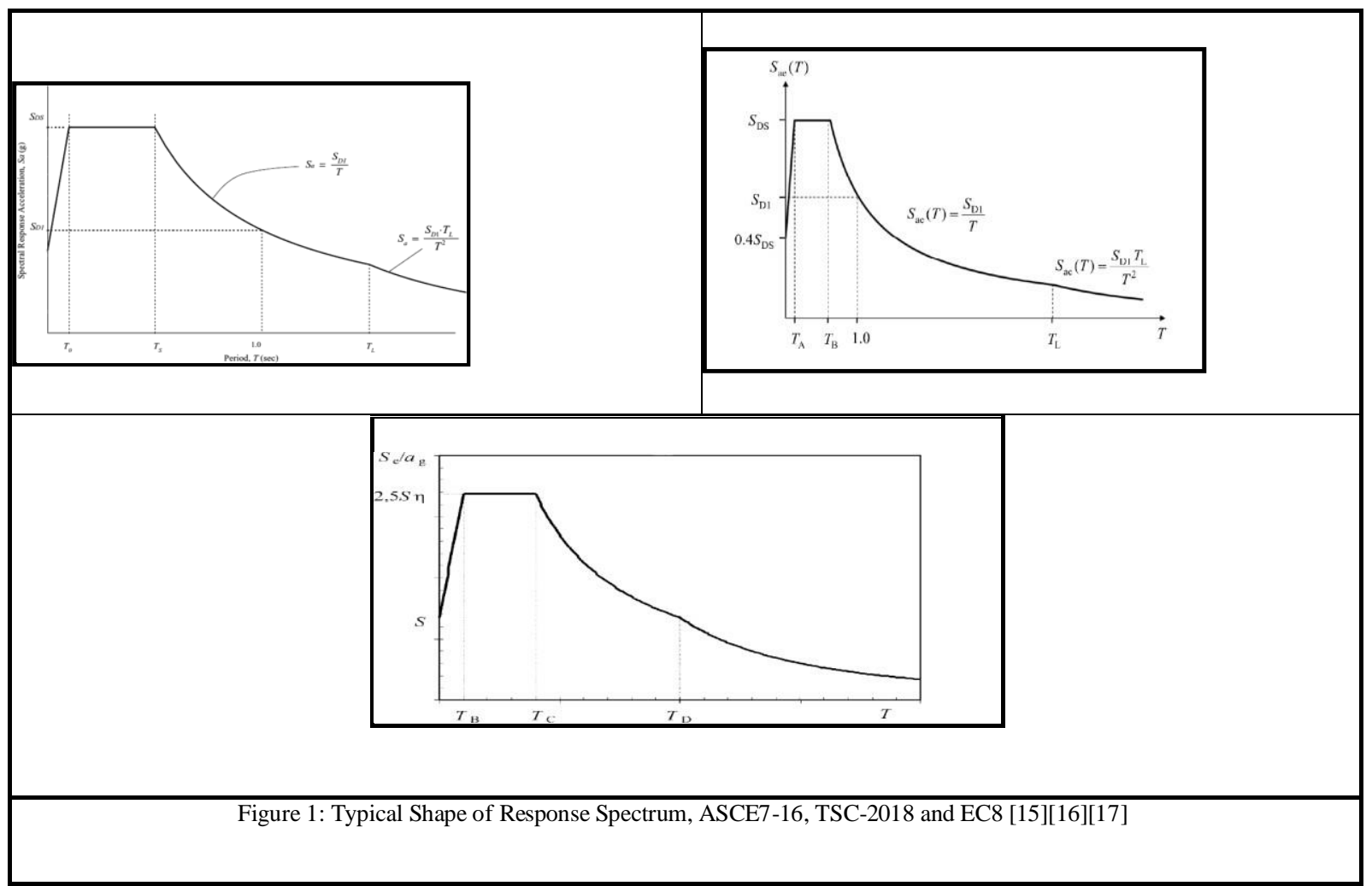

Table 2 Elastic ordinates defined by seismic codes

\begin{tabular}{|ccc|}
\hline TSC-2018 & ASCE7-16 & EC8-2004 \\
$0 \leq \mathrm{T} \leq \mathrm{T}_{\mathrm{A}}$ & $0 \leq \mathrm{T} \leq \mathrm{T}_{\mathrm{A}}$ & $0 \leq \mathrm{T} \leq \mathrm{T}_{\mathrm{B}}$ \\
$\mathrm{S}_{\mathrm{ae}}(\mathrm{T})=\left(0.4+0.6 \frac{\mathrm{T}}{\mathrm{T}_{\mathrm{A}}}\right) \mathrm{S}_{\mathrm{DS}}$ & $\mathrm{S}_{\mathrm{ae}}(\mathrm{T})=\left(0.4+0.6 \frac{\mathrm{T}}{\mathrm{T}_{\mathrm{A}}}\right) \mathrm{S}_{\mathrm{DS}}$ & $\mathrm{S}_{\mathrm{e}}(\mathrm{T})=a_{g} \cdot s\left(1+\frac{T}{T_{A}} \cdot(\eta \cdot 2.5-1)\right)$ \\
$T_{A} \leq \mathrm{T} \leq \mathrm{T}_{\mathrm{B}}$ & $\mathrm{T}_{\mathrm{A}} \leq \mathrm{T} \leq \mathrm{T}_{\mathrm{B}}$ & $T_{\mathrm{B}} \leq \mathrm{T} \leq \mathrm{T}_{\mathrm{C}}$ \\
$\mathrm{S}_{\mathrm{ae}}(\mathrm{T})=\mathrm{S}_{\mathrm{DS}}$ & $\mathrm{S}_{\mathrm{ae}}(\mathrm{T})=\mathrm{S}_{\mathrm{DS}}$ & $\mathrm{S}_{\mathrm{e}}(\mathrm{T})=a_{g} \cdot \mathrm{s} \cdot \eta \cdot 2.5$ \\
$\mathrm{~T}_{\mathrm{B}} \leq \mathrm{T} \leq \mathrm{T}_{\mathrm{L}}$ & $\mathrm{T}_{\mathrm{B}} \leq \mathrm{T} \leq \mathrm{T}_{\mathrm{L}}$ & $\mathrm{T}_{\mathrm{C}} \leq \mathrm{T} \leq \mathrm{T}_{\mathrm{D}}$ \\
$\mathrm{S}_{\mathrm{ae}}(\mathrm{T})=\frac{\mathrm{S}_{\mathrm{D} 1}}{\mathrm{~T}}$ & $\mathrm{~S}_{\mathrm{ae}}(\mathrm{T})=\frac{\mathrm{S}_{\mathrm{D} 1}}{\mathrm{~T}}$ & $\mathrm{~S}_{\mathrm{e}}(\mathrm{T})=a_{g} \cdot \mathrm{s} \cdot \eta \cdot 2.5\left(\frac{\mathrm{T}_{\mathrm{C}}}{\mathrm{T}}\right)$ \\
$\mathrm{T}_{\mathrm{L}} \leq \mathrm{T}$ & $\mathrm{T}$ & $\mathrm{T}_{\mathrm{L}} \leq \mathrm{T}$ \\
$\mathrm{S}_{\mathrm{ae}}(\mathrm{T})=\frac{\mathrm{S}_{\mathrm{D} 1} \mathrm{~T}_{\mathrm{L}}}{\mathrm{T}^{2}}$ & $\mathrm{~S}_{\mathrm{ae}}(\mathrm{T})=\frac{\mathrm{S}_{\mathrm{D} 1} \mathrm{~T}_{\mathrm{L}}}{\mathrm{T}^{2}}$ & $\mathrm{~T} \leq 4 \mathrm{~s}$ \\
\hline
\end{tabular}

\section{REDUCTION FACTOR}

The seismic design codes specify the inelastic dissipation energy effects to design to reduce the design force. Despite Seismic codes are use different for the design, but commonly seismic codes use force based methodology. However, the classification according to the structural type is different such as detailing, detailing significantly affects the structural strength, and the elastic response spectrum shape as well is different[18]. However, seismic codes considers reduction factor which structures hold the capacity to resist earthquake beyond the elastic limit, structures will be expected to behave non-linear variety, producing huge deformation and dissipating an enormous quantity of energy, according to this the structures will be intended and detailed imperatively to convince the essential capacity of energy dissipation[19]. The supply of ductility in structural system tolerates the reduction of elastic response spectrum, ductility reduction factor generally rely upon the period of structure. Seismic codes describes reduction factors changing in to elastic spectra in design spectra in a purpose of structural systems, mostly the reduction factors defines the purpose of ductility classes. In addition to seismic codes use for different ductility 
classes ASCE7 defines three ductility classes, Ordinary Moment Resistance Frame, Intermediate Moment Resistance Frame and Special Moment Resistance Frame and TSC-2018 considered three ductility classes Ordinary Moment Resistance Frame, Intermediate Moment Resistance Frame, and Special Moment Resistance Frame and each one is corresponding to different reduction factor. Eurocode 8 classifies the ductility classed in to three, high ductility class, medium and low ductility respectively

Table 3 Ductility classes

\begin{tabular}{|c|c|c|c|c|c|c|}
\hline \multirow[b]{2}{*}{ Category } & \multicolumn{6}{|c|}{ Ductility classes } \\
\hline & \multicolumn{2}{|c|}{ ASCE7-16 } & \multicolumn{2}{|c|}{ EC8 } & \multicolumn{2}{|c|}{ TSC-2018 } \\
\hline 1- Low dissipative structures & OMRF & 3 & DCL & 1.5 & OMRF & 3 \\
\hline 2- Medium dissipative structures & IMRF & 5 & DCM & 3.9 & IMRF & 5 \\
\hline 3- High dissipative structures & SMRF & 8 & $\mathrm{DCH}$ & 5.85 & SMRF & 8 \\
\hline
\end{tabular}

\section{DRIFT CONTROL}

The prevention and awareness for non-structural and structural damages for structures, the past decades become prominence for the building located by seismic areas, exclusively subsequent reflection on the catastrophic left by seismic actions. Story drift defined by the percentage among the two floors divided by the height of the floor[20]. It is vital and essential to describe the story drift. Building codes provide guidelines to reduce the potential damage to the structures caused by serve earthquakes. Nevertheless, the valuation and design of structures should be established the earthquake demand for inelastic deformations. Under low to medium for intensity seismic actions, the building codes limited the damage. The seismic design emphasizes to control the damage of non-structural damage by limiting the inter-story drift. Elastic displacement at floor level is computed and amplified by deflection amplification factor which rely on the structural type of the building [21]. This amplification (Cd) has been used to account the inelastic deformation of the building. According to the Eurocode 8, elastic displacement has been limited by amplified behavior factor directly. Turkish code consider modification factor to amplify the elastic displacement. Building codes limits the story drift, and American code allows up to $2.5 \%$ for ordinary moment multi story frame buildings, and Eurocode 8 drift depends on the type of non-structural elements and allows $1 \%$ for buildings having brittle non-structural elements, and building having ductile elements $1.5 \%$ and buildings having without non-structural elements for 2\%[22][23].

\section{BUILDING MODEL}

A particular location has chosen to achieve a better comparison among seismic codes, and Avclilar in Istanbul has chosen. The regular building has four bays, both longitudinal and transverse direction $(20 \mathrm{~m})$, and the geometry of the building presented by Fig 2. The total height of the building is $18 \mathrm{~m}$ and the building designed by a high seismic zone with medium soil. The ground motion designed a moderate or level DD-2 as described by Turkish code, which describes a $10 \%$ probability of exceeding in 50 years, corresponding to a return period of 475 years for very stiff soil. The compressive strength assumed M25 and reinforcement steel S420, the structural elements such as beams $(30 \times 50) \mathrm{mm}$, columns $(50 \times 50) \mathrm{mm}$, and thickness of slab $150 \mathrm{~mm}$ used for design, respectively. Table 4 describes all the details about the preliminary data used for the design. In this study the stiffness reduction factors has been considered for the design.

Table 4 Preliminary Data

\begin{tabular}{|c|c|c|c|}
\hline \multirow[b]{4}{*}{$\begin{array}{l}\text { Occupancy category } \\
\text { Importance factor }\end{array}$} & TSC-2018 & ASCE7-16 & EC8 \\
\hline & D & $\mathrm{D}$ & $\mathrm{C}$ \\
\hline & $\mathrm{S}_{\mathrm{S}}=1.08$ & $\begin{array}{l}S_{S}=1.08 \\
S_{1}=0.296\end{array}$ & $\mathrm{ag}=0.44 \mathrm{~g}$ \\
\hline & II & $\begin{array}{l}\text { III } \\
1.2\end{array}$ & II \\
\hline & 1.2 & & 1.2 \\
\hline Reduction factor & 5 & 5 & 5.85 \\
\hline \multicolumn{4}{|c|}{ Cracked stiffness ratio } \\
\hline Column & 0.7 & 0.7 & 0.5 \\
\hline Beam & 0.35 & 0.35 & 0.5 \\
\hline Slab & 0.25 & 0.25 & 0.25 \\
\hline
\end{tabular}




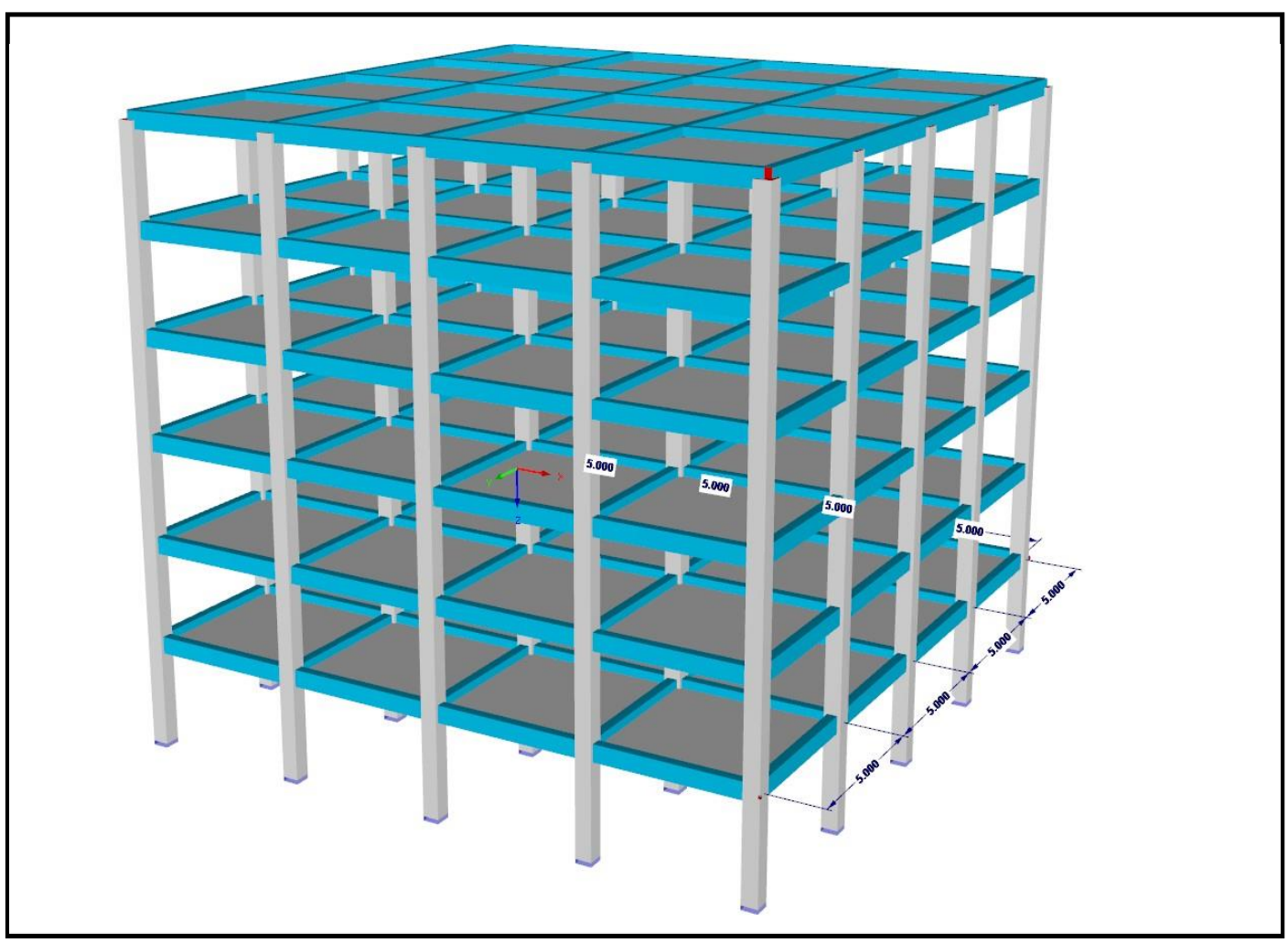

Modal Analysis

Figure 2: 3D Model

The response spectrum is a widely accepted method for earthquakes resistance design. Boit developed, and Housner improved it later. This method plots the maximum response of a single degree of freedom corresponding to the natural period in terms of acceleration, velocity, and acceleration. Most seismic codes use acceleration elastic response spectra. For a given earthquake, the design spectra considered the peak values of the performance of each variation mode is a computed modal combination method. The peak values achieved by each mode combined either SRSS or CQC. This study, the CQC, used to combine the maximum modal contributions, and the modal damping assumed should be $5 \%$ for all modes. The modal response spectrum in modes should not be less than $90 \%$ the mass of the structure (EC8-2004), while American code considers $90 \%$ the modal analysis in base shear force [24][25]. The design implemented by using SAP 2000.v.20.

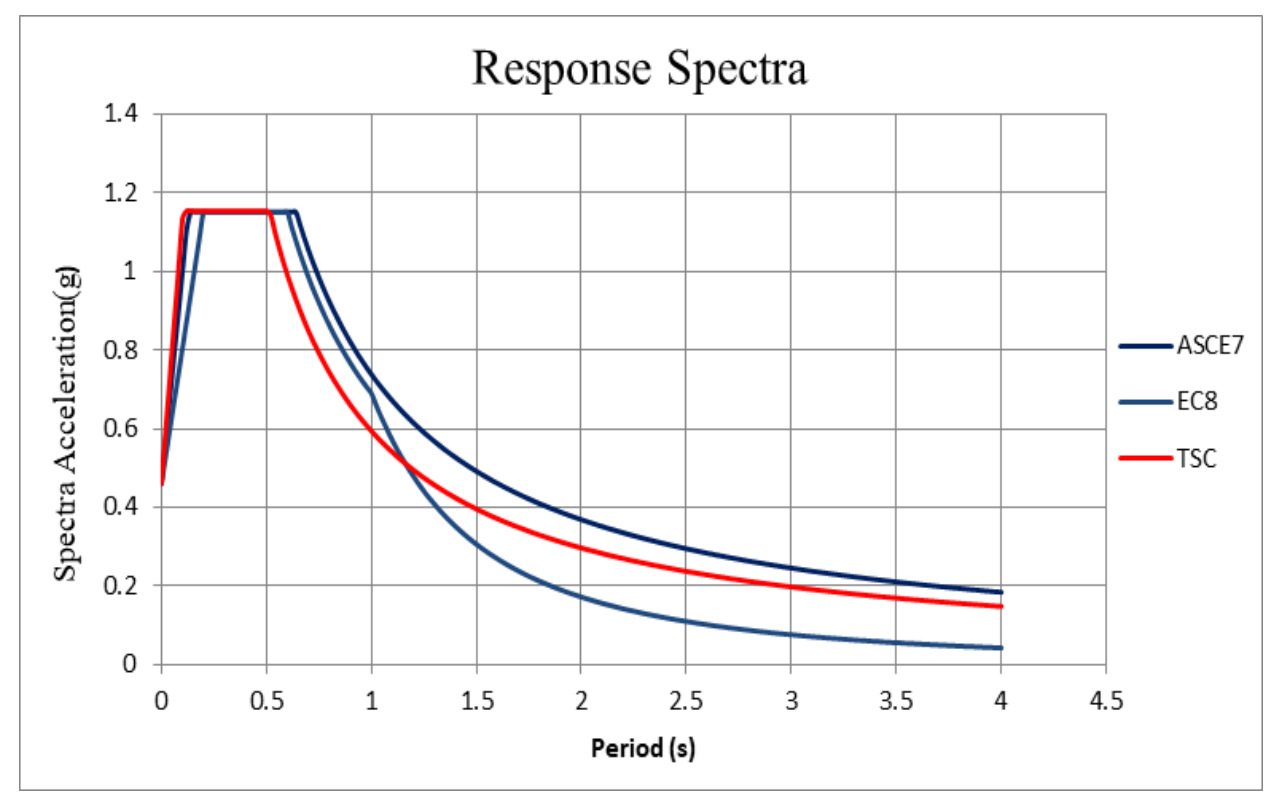

Figure 3: Elastic response spectrum 


\section{ANALYSIS AND RESULTS}

To compare seismic codes fairly, the elastic spectra have been used for the analysis, and considered reduction and behavior factors due to the nonlinear behavior. SAP 2000 program have been performed the spectral analysis of the building. The base shear of the building has been obtained from modal response spectra corresponding to the 5\% of critical damping. Three different seismic codes used for the design to achieve their distinction, it has been observed that highest base shear obtained the Turkish code and nearby the Eurocode code and minimum base shear obtained American code. The base shear obtained modal analysis has been scaled to the equivalent lateral force to depict that meets the required percentage that codes recommended. The variation results may be caused the design spectra, effective stiffness members and modification factor and most importantly the period of the bundling.

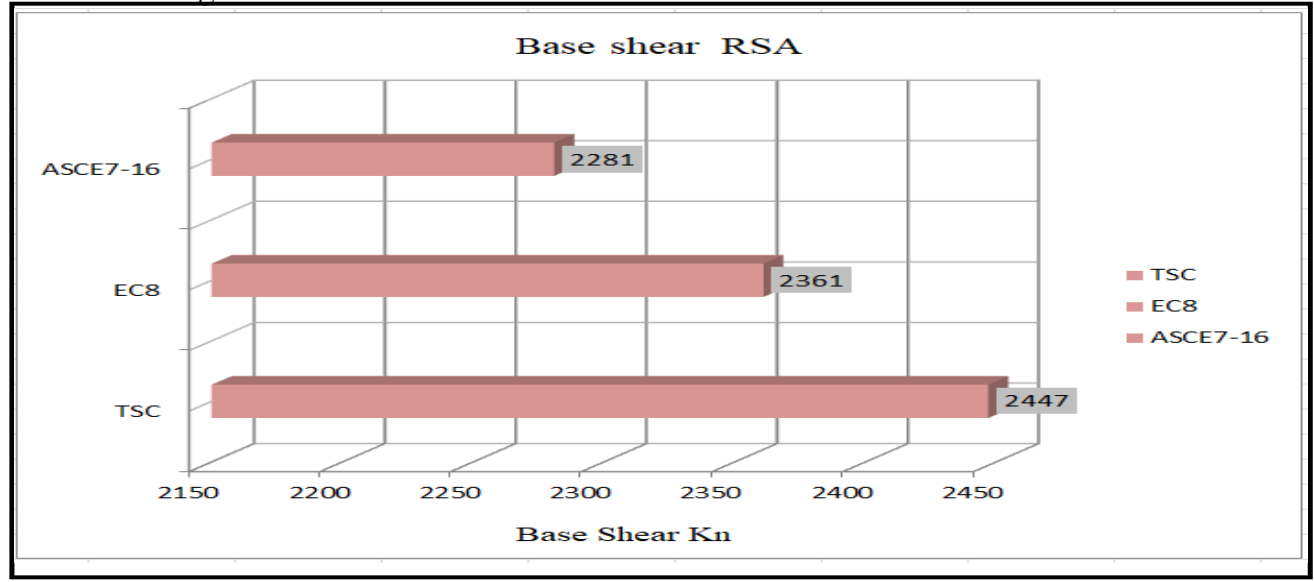

Figure 4: Base shear

The first ten mode shapes with corresponding to the periods and mass participating mass ratios has been presented in Table 5 . The effective modal mass has been obtained more than $90 \%$ for each seismic code both horizontal directions. Seismic codes recommended that effective modal mass should not be less than $90 \%$ the total mass of the building.

Table 5 First ten modes and modal participating ratios of the building

\begin{tabular}{|ccccc|}
\hline & & & Cumulative sum \% & Y \\
Case & & Mode Period (s) & X & 0.65635 \\
modal & 1 & 0.783646 & 0.79314 & 0.79314 \\
modal & 2 & 0.236525 & 0.81246 & 0.88551 \\
modal & 3 & 0.121646 & 0.90483 & 0.90483 \\
modal & 4 & 0.074653 & 0.91649 & 0.94187 \\
modal & 5 & 0.06359 & 0.95353 & 0.95353 \\
modal & 6 & 0.061391 & 0.96074 & 0.97315 \\
modal & 7 & 0.057788 & 0.98035 & 0.98036 \\
modal & 8 & 0.055684 & 0.98035 & 0.98036 \\
modal & 9 & 0.052549 & 0.98036 & 0.98036 \\
modal & & 100.052107 & \\
\hline
\end{tabular}

Story drift is essential damage indicator parameter; however, the seismic code limits the drift story for a range and depends on the structural type of building, ASC7 code uses a deflection amplifications factor to calculate the inelastic deformations. The results has been obtained using American codes depicts that story drift is under limit. But the results obtained Eurocode shows that some story exceeded the story drift limit especially, the structure having non-structural elements. Eurocode use a behavior factor to amplify the elastic displacement. The results obtained a new Turkish code describes under safe when compared the result obtained the drift limit that code is required. Turkish code uses a reduction factor to account the inelastic deformation caused by nonlinear behavior.

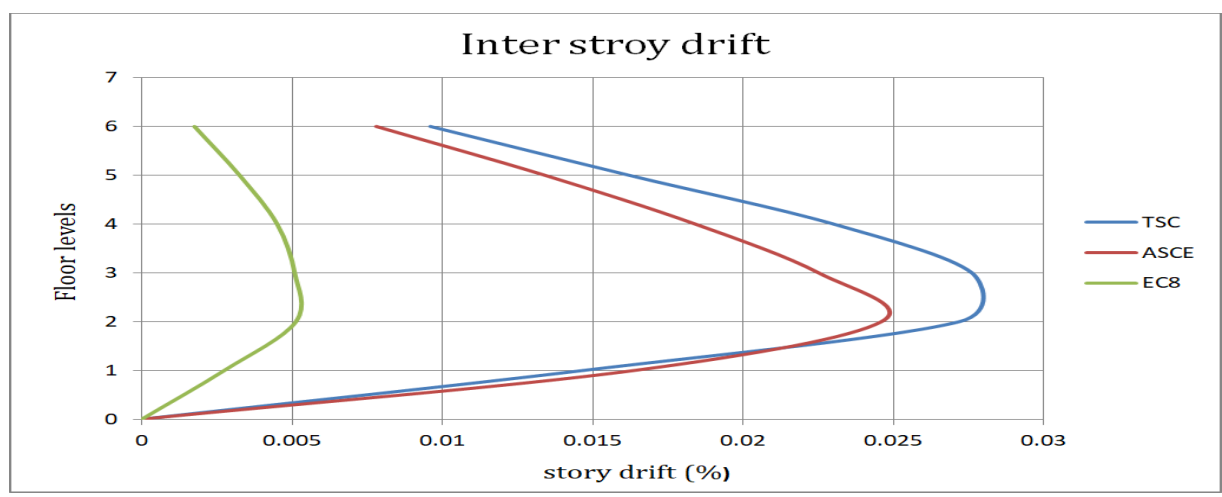

Figure 5: story drift 


\section{CONCLUSION}

In this study, the seismic codes USA, TSC-2018, and EC8 have been compared; the primary purpose of the comparison is to investigate the similarity and difference among them. Many standard building codes developed and enforced to minimize damage and to ensure life safety and economic loss. Seismic codes designed and set a minimum requirement to mitigate the hazards of earthquakes. In seismic regions, seismic design is very sensitive. Nonetheless, the absence of seismic design codes, engineers depends on international guidelines. Therefore it is imperative to compare the international design codes once the building codes developed. In this study, a particular site has chosen to achieve the comparison codes. The result obtained the design codes compared and highlighted by the similarity and difference among them, such as base shear, inter-story drift, and displacement. The dynamic linear analysis used to implement the design to achieve the main objectives and the analysis is performed in SAP 2000. V20.

The design spectra are the main difference among these seismic codes. However, codes describe for ground motion design on different levels. The Turkish seismic code describes four different ground motions for a return period of earthquake DD-1: 2\% probability of exceeding in 50 years, and return is 2475 , DD-2: $10 \%$, probability of exceeding in 50 years, and recurrence are 475, DD-3: $50 \%$ probability of exceeding in 50 years, and recurrence is 72 and finally DD-4: $50 \%$ probability of exceeding in 50 years. EC 8 defines the seismic hazard at $10 \%$ probability exceedance in 50 years for return period 475 years as the reference of the seismic action. ASCE7-16 defines the return period 2475 years, the probability of $2 \%$ seismic inputs exceeded in 50 years, matching the MCER.

Building codes are different for the calculations inter story drift, and codes use reduction factor or behavior to account the inelastic deformations caused by nonlinear behavior. American code us deflection amplification factor to amplify the elastic displacement to account inelastic deformation where Eurocode use behavior factor and Turkish code use a reduction factor respectively.

The base shear obtained spectral analysis using modal response spectrum shows that Turkish code provided us the highest base shear despite close to the Eurocode, however, the minimum base shear obtained American code(ASCE7-16). The variation may cause the design spectra, modification factors and most importunely the period of the building.

\section{REFERENCES}

[1] Erdick M (2004) Report on 1999 Kocaeli and Düzce (Turkey) earthquakes

[2] Asena, Soyluk., Zeynep, Yesim. Harmankaya (2012) History of Development in Turkish Seismic Design Codes

[3] Murat, Bikce., Tahir, Burak. Çelik (2016) Analysis of newly constructed RC buildings designed according to 2007 Turkish Seismic Code during the October 23, 2011 Van earthquake Engineering Failure Analysis 64 (2016) 67-84

[4] M, B. Waris, H. Saeed, K. S. Al-Jabri, and I. El-Hussain (2017). Comparison of Oman Seismic Code for Buildings with International Counterparts, 16th World Conference on Earthquake, 16WCEE 2017

[5] Tariq, M. Nahhas (2018) A Comparison of Saudi Building Code with 1997 UBC for Provisions of Modal Response Spectrum Analysis Using a Real Building. Open Journal of Earthquake Research, 2017, 6,98-116

[6] M, D. Trifunac (2008). 75th Anniversary of the response spectrum method - A historical review Soil Dynamics and Earthquake Engineering, 2008 28: pp. 675 .

[7] M, D. Trifunac and M.I. Todorovska (2008). Origin of the Response Spectrum Method the 14th World Conference on Earthquake Eng ineering October 12-17, 2008, Beijing, China

[8] Mihailo, D. Trifunac (2008). Historical Review Early history of the response spectrum method" Soil Dynamics and Earthquake Engineering 28 (2008) 676-685)

[9] S. H. C. Santos, C. Giarlelis, M. Traykova, C. Bucur, L. Zanaica, S. S. Lima (2017) Comparative Study of a Set of Codes for the Seismic Design of Buildings. 39th IABSE Symposium - Engineering the Future September 21 - 23 2017, Vancouver, Canada

[10] Haluk, Sucuoglu (2018) New Improvements in the 2018 Turkish Seismic Code International Workshop on

[11] Advanced materials and innovative systems in structural engineering

[12] Amina, Chebihi., and Nasser, Laouami (2014) Comparative Seismic Study between Algerian Code (Rpa99), European Code (Ec8) and American Code (Ubc97) second European conference earthquake engineering and seismology, Istanbul in 24-29, 2014

[13] R. Verdugo, and G. Peters (2017) Seismic Soil Classification and Elastic Response Spectra 16th World Conference on Earthquake Engineering, 16WCEE 2017 Santiago Chile, January 9th to 13th 2017

[14] Doğangün, Adem, Livaoğlu, R. (2006) A comparative study of the design spectra defined by Eurocode 8 ,

[15] UBC, IBC and Turkish Earthquake Code on R/C sample buildings Journal of Seismology, 3, 335-351

[16] Vijay Namdev, Khose, Yogendra Singh, Dominik Lang (2012) A Comparative Study of Design Base Shear for RC Buildings in Selected Seismic Design Codes

[17] Turkish Earthquake Code (2018), Specification for Structures to be built in Disaster Areas Ministry of Public Works and Settlement, Government of Republic of Turkey

[18] EN 1998-1: 2004 Eurocode 8, Design of Structures for Earthquake Resistance- Part 1: General Rules, Seismic Actions and Rules for Buildings.

[19] ASCE/SEI 7-16. Minimum Design Loads and Associated Criteria for Buildings and Other Structures

[20] Ahmed, M. El-Kholy., Hoda .Sayed., and Ayman, A. Shaheen (2013) Comparison of Egyptian Code 2012 with Eurocode 8-2013, IBC 2015 and UBC 1997 for seismic analysis of residential shear-walls RC buildings in Egypt. Ain Shams Engineering Journal 9 (2018) 3425-3436

[21] Yogendra, Singh., and Vijay, Namdev. Khose, (2010) Comparative study of code provisions for ductile RC frame buildings

[22] Nouredine, Bourahla. (2013) Equivalent Static Analysis of Structures Subjected to Seismic Actions Encyclopedia of Earthquake Engineering DOI 10.1007/978-3-642-36197-5_169-1

[23] Mohammad, Azim. Eirgash(2019) A Comparative Study of Seismic Performance of the Building Designed using Four Major Codes International Journal of Engineering Research \& Technology (IJERT) Vol. 8 Issue 08, August-2019

[24] M, Soós., and L, G. Vigh, (2012) On the Eurocode 8 limited damage criteria for non-structural elements -Analysis and requirements

[25] Altin, Seranaj., Forcim, Softa., Agim, Seranaj, and Fanjola, Koroveshi (2012) Damage limitation requirements according Eurocode 8 for flexible reinforced concrete low-rise buildings. 3rd International Balkans Conference on Challenges of Civil Engineering, 3-BCCCE, 19-21 May 2016, Epoka University, Tirana, Albania

[26] Mehdi, Ahmadizadeh (2007) Evaluating the effects of ground motion parameters on response spectra of Iranian Earthquakes

[27] Shehata, E. Abdel Raheem (2013) Evaluation of Egyptian code provisions for seismic design of moment resisting- frame multi-story buildings. International Journal of Advanced Structural Engineering December 20 